\title{
POLÍTICA DE AÇÕES AFIRMATIVAS E OS ESTUDANTES INDÍGENAS DO INSTITUTO DE CIÊNCIAS DA EDUCAÇÃO (ICED): VIVÊNCIAS E DESAFIOS NOS 10 ANOS DA UNIVERSIDADE FEDERAL DO OESTE DO PARÁ (UFOPA)*
}

\author{
Wania Alexandrino Viana ${ }^{1}$ \\ Elenise Pinto de Arruda ${ }^{2}$
}

No dia 17 de janeiro de 2019, por ocasião do lançamento da campanha para celebrar os 10 anos da Universidade Federal do Oeste do Pará (Ufopa), a palavra conexão foi apresentada como o conceito que sintetizava e definia as ações da instituição nessa uma década de existência. Essa escolha foi justificada pelos criadores do conceito em razão da sugerida identidade que constitui uma universidade estabelecida no interior da Amazônia. Tal condição seria a razão para uma intrínseca relação entre a instituição, a diversidade e os saberes que compõem esse território.

De fato, trata-se de um espaço compósito e diverso, sobretudo do ponto de vista da diversidade cultural, linguística e étnica. Basta lembrar que o Censo 2010 do Instituto Brasileiro de Geografia e Estatística (IBGE) apontou uma população de 51.217 indígenas no Pará. A área de abrangência da Ufopa, estimada em seu Plano de Desenvolvimento Institucional em 13 municípios, além dos seis dos que têm campi e da sede, totalizando 20 municípios, representa essa diversidade étnica, posto que essa área tem, de acordo com o Censo 2010, aproximadamente 15.848 habitantes indígenas e, segundo a Fundação Nacional do Índio (Funai, 2018), 21 terras indígenas com 28 etnias presentes.

Tal quadro imprime especificidades ao ensino e impõe necessário diálogo entre as universidades da Amazônia e a sociodiversidade desse espaço. O conceito da campanha, portanto, parece querer apontar para a relação que essa

\footnotetext{
${ }^{*}$ DOI - 10.29388/978-65-86678-64-2-0-f.69-84

${ }^{1}$ Professora da Universidade Federal do Oeste do Pará (Ufopa). Doutora em História Social da Amazônia pelo Programa de Pós-Graduação em História Social da Amazônia da Universidade Federal do Pará (UFPA). Desenvolve pesquisas na área de história da Amazônia colonial, com ênfase em defesa, militarização, fronteira, guerras e história indígena. Integra o grupo de pesquisa História Indígena e Indigenismo na Amazônia (Hindia), da UFPA. Atualmente, é membro da Comissão Setorial de Acompanhamento das Ações Afirmativas do Instituto de Ciências da Educação (Iced/Ufopa).

${ }^{2}$ Mestra em Educação. Pedagoga da Ufopa. Ex-diretora de Ações Afirmativas e membro da Comissão Setorial de Acompanhamento das Ações Afirmativas do Iced/Ufopa.
} 
instituição estabelece com a diversidade humana da região em que se insere. Nessa perspectiva, neste texto busca-se refletir sobre a relação da Ufopa com os povos indígenas da região.

É interesse deste capítulo verificar essa conexão referida na campanha a partir de duas abordagens: primeiro, pela análise das políticas afirmativas desenvolvidas pela instituição nos 10 anos. Segundo, a partir dos desafios enfrentados pelos estudantes indígenas na vivência acadêmica. Trata-se, especificamente, de verificar os alunos indígenas dos cursos de graduação do Instituto de Ciências da Educação (Iced) e, em particular, os discentes matriculados no curso de Licenciatura em História. Essa reflexão constitui-se a partir das atividades desenvolvidas pela Comissão Setorial de Ações Afirmativas do Iced, da qual fazemos parte. A escolha do tema deve-se à participação na Comissão.

É importante lembrar que, se a campanha dos 10 anos da Ufopa pretende colocar a universidade em conexão com os povos indígenas, é também possível afirmar que, para esses sujeitos, o ingresso na universidade é, sobretudo, a afirmação de suas existências. Resultado de um processo recente na história do Brasil, no qual o acesso aos espaços de formação superior foi excludente para grande parte dos brasileiros.

\section{1. "Da negação à afirmação da 'existência' indígena": as políticas de ações afirmativas}

Em primeiro lugar, convém ressaltar que o ensino institucionalizado no Brasil, para as populações indígenas, esteve ancorado em um projeto excludente e de negação de suas existências culturais. A presença desses grupos sociais nas instituições de ensino superior é, sobretudo, decorrente de um processo de afirmação política e étnica. A Constituição de 1988 é considerada um marco para a mudança de conduta do Estado brasileiro para com os povos indígenas. A partir de então, é-lhes assegurado o direito à diferença, à diversidade e ao ensino diferenciado.

Todavia, o indígena no ensino superior é um fenômeno ainda mais recente. Foi a partir do ano 2000 que se verificaram no Brasil políticas voltadas ao acesso diferenciado às universidades e agendas mais sistemáticas de promoção da justiça social e da equidade educacional. Esse movimento de transformação está relacionado com as políticas de ações afirmativas, que são norteadas por quatro argumentos centrais: 1) justiça compensatória; 2) promoção do pluralismo; 3) justiça distributiva; e 4) fortalecimento da identidade e da autoestima do grupo favorecido. 
A justiça compensatória refere-se ao reconhecimento e à "retificação de injustiças ou falhas cometidas contra indivíduos no passado, ora por particulares, ora pelo governo" (Kaufmann, 2007, p. 222). Essa premissa alcança a experiência histórica dos povos indígenas no Brasil. Para Gersem Baniwa, no longo período entre 1500 e 1988, as políticas para os índios caracterizaram-se pela assimilação e integração. O ensino, por exemplo, estava voltado para "que fossem extintos como povos étnicos" (Baniwa, 2013, p. 1).

Tal paradigma fazia entender os indígenas como categorias sociais transitórias, tendo forte caráter colonizador. A construção da imagem dos índios reduziu a diversidade étnica aos quadros de compreensão ocidental, configurando-se em um importante elemento da negativação do indígena (Raminelli, 1996). Esse processo correspondia aos mecanismos de dominação indígena, conforme explica Manuela Carneiro da Cunha (1990).

Nesses termos, estabeleciam-se as bases para sua transformação. Ora, gentios, selvagens, bárbaros, pagãos e muitos outros adjetivos passaram a prefigurar as narrativas sobre os indígenas e convergiam para duas estratégias: legitimar a colonização e reafirmar a importância da cristianização desses povos. Um código de transição, que incluía a língua, o nome, o batismo e o espaço de vivência, cujo escopo era a transformação do índio em cristão e em civilizado. Como destacou John Monteiro (2005), esses eram mecanismos de um caminho de integração do índio do sertão em índio colonial. Essa orientação era também prevista na Lei do Diretório dos Índios, de 1755, que dava liberdade aos índios, mas inseria-os em um processo de assimilação da cultura ocidental e de abandono de suas práticas culturais (Coelho, 2005).

Essa conduta assimilacionista e reducionista do período colonial foi absorvida pelo Estado brasileiro no século XIX. Para Maria Regina Celestino de Almeida, tal política foi ainda acentuada. A ausência de uma política indigenista mais sistemática, até pelo menos o Regimento das Missões, de 1845, corroborou a manutenção no Oitocentos das práticas da política de Pombal, já lançada desde meados do século XVIII (Almeida, 2012, p. 22). Nesse contexto, em decorrência dos processos de civilização e mestiçagem, o desaparecimento indígena parecia um caminho inevitável. Tal perspectiva atrelava-se à construção do nacionalismo enquadrado nas orientações europeias, para o qual "não havia lugar para pluralidades étnicas e culturais” (Almeida, 2012, p. 22).

A justiça compensatória, que sustenta a legitimidade das políticas de ações afirmativas, deve, portanto, ser compreendida na interpretação histórica da relação do Estado brasileiro com os povos indígenas e das políticas indigenistas implementadas desde o contato. Ora, a escravização, as guerras, o extermínio cul- 
tural, a apropriação de suas terras, a inferiorização étnica, a exclusão social e a negação da pluralidade dos povos indígenas não podem estar desconectados ao tratar-se das políticas afirmativas contemporâneas. Afinal, elas se justificam a partir dessa compreensão histórica.

Outro argumento da política de ações afirmativas é a promoção do pluralismo. Deve-se ao reconhecimento da histórica negação da diversidade étnica e cultural dos povos indígenas. É um processo verificável nas políticas indigenistas a partir da interpretação dos "povos indígenas como culturas em estágios inferiores, cuja única perspectiva é a integração e a assimilação à cultura global" (Baniwa, 2013, p. 34). Tais políticas fundamentam-se, sobretudo, na homogeneização cultural.

Essa construção integraria também as bases para a constituição de instituições voltadas aos índios. É o que se verifica em um período denominado indigenismo governamental tutelar, caracterizado pela criação e atuação do Serviço de Proteção ao Índio (SPI), em 1910, e, mais tarde, pela Funai, em 1967. Legitimava-se a tutela indígena pela ideia vigente de "incapacidade civil e intelectual dos índios". O Estado, nesses termos, deveria ser porta-voz e representante dos povos indígenas (Baniwa, 2006).

A promoção do pluralismo assevera a diversidade étnica e cultural que constitui o Brasil. Fundamenta-se na liberdade e no direito à diferença. E, no que se refere aos povos indígenas, afirma-se o direito a suas tradições, conhecimentos, língua e cultura. Um processo importante, se considerarmos as políticas assimilacionista e integracionista que lhes foram impostas, as quais asseguravam o desaparecimento étnico dos índios. De todo modo, na contramão do desaparecimento, conforme explica Márcio Couto Henrique, "os índios não desapareceram com o impacto da mudança". Mais do que isso, "contribuíram para mudança daqueles que pretendiam civilizá-los" (Henrique, 2018, p. 221). Para Celestino de Almeida (2012), os indígenas passaram da invisibilidade do século XIX ao protagonismo nos séculos XX e XXI.

Essa mudança decorre de dois processos: a ação política dos indígenas e a abertura política. O primeiro está vinculado aos movimentos indígenas, entendidos aqui como "conjunto de estratégias e ações que as comunidades e organizações indígenas desenvolvem em defesa de seus direitos e interesses coletivos" (Baniwa, 2006, p. 58). No Brasil, a partir da década de 1970, é possível verificar a atuação conjunta de diversos grupos indígenas, que se articularam com outros setores da sociedade em torno de pautas comuns de lutas, como pela terra, saúde, educação e por outros direitos. 
Integraram a discussão sobre a condição indígena, por exemplo, a Igreja Católica Renovada, por meio da Conferência Nacional dos Bispos do Brasil (CNBB), no âmbito do Conselho Indígena Missionário (CMI), além de organizações civis e das universidades, que atuaram no fortalecimento das pautas de lutas dos povos indígenas. Nessa direção, verifica-se a ação de organizações não governamentais (ONGs) de apoio indígena, como a Operação Amazônica Nativa (Opan), o Centro de Trabalho Indigenista (CTI), a Comissão Pró-Yanomami (CCPY), o Instituto Socioambiental (ISA), a Associação Nacional de Ação Indigenista (Anai), entre outras, que caracterizaram um indigenismo não governamental (Baniwa, 2006).

Da invisibilidade ao protagonismo histórico, os povos indígenas organizaram-se regional, nacional e internacionalmente. Uma conjuntura política marcada por lutas e atuação de lideranças indígenas, que culminaram em importantes conquistas na Constituição de 1988. Exemplar nesse sentido é o deslocamento das perspectivas integracionista e assimilacionista para o reconhecimento da diferença, assegurado pelo reconhecimento étnico e cultural, além do direito originário à terra, da legitimação da autonomia societária dos povos indígenas, do reconhecimento do direito à cidadania híbrida, étnica, nacional e global.

A justiça distributiva, como terceiro argumento das políticas de ações afirmativas, tem a ver como esse novo momento histórico de organização e atuação política dos povos indígenas. Se a justiça compensatória volta-se para o passado, a distributiva desloca-se para o presente, pois fundamenta-se na "distribuição de direitos, benefícios e obrigações entre os membros da sociedade", a fim de promover igualdade de oportunidades, em vista de uma sociedade equânime e justa (Jensen, 2010, p. 56).

Essa compreensão deve-se, em grande parte, à atuação e à participação indígena. Exemplar nesse sentido é o fenômeno político da etnogênese, verificável na afirmação étnica e no impulso das pautas coletivas pela ampliação dos direitos. Trata-se da identificação étnica como estratégia para acionar direitos garantidos pela Constituição de 1988. Além disso, configura-se como caminho para a sobrevivência social. Todavia, não se trata apenas disso; essa emergência "concorre igualmente [com] o desejo de pertencer a um povo, a um lugar e a uma luta" (Peixoto, Arenz e Figueiredo, 2012, p. 285).

Portanto, apesar da visão limitada e discriminatória que historicamente pautou a relação entre índios e brancos no Brasil e do desdobramento em "uma série de ambiguidades e contradições, que podem ser observados, ainda hoje, na sociedade brasileira", os grupos indígenas estão em movimento, reafirmando-se 
politicamente e contrariando as perspectivas do desaparecimento do século XIX (Baniwa, 2013, p. 34).

Essa perspectiva identitária corresponde ao quarto argumento das políticas de ações afirmativas. Justifica-se pela promoção do fortalecimento da identidade e da autoestima do grupo favorecido. Ao considerar-se o enraizado preconceito, a discriminação e a exclusão dos grupos indígenas, torna-se patente a necessidade de ações mais incisivas para a construção de estratégias de valorização étnica, acesso a direitos e positivação do indígena como sujeito politicamente atuante.

Esse brevíssimo percurso histórico, atrelado aos princípios de justificação das políticas de ações afirmativas, aponta que os povos indígenas integram um longo período de negação étnica e cultural. Essa reflexão é fundamental para a compreensão da importância dos indígenas nas universidades. Voltando ao ponto inicial, se a campanha dos 10 anos da Ufopa busca imprimir um conceito de conexão no que diz respeito à diversidade sociocultural e étnica da Amazônia, é importante compreendê-la nos quadros das lutas dos povos indígenas em estar presente, em fazer-se existência. Nesta altura, entretanto, convém verificar a aludida relação da instituição como os povos indígenas da região.

\section{2. "Ultrapassar muros": políticas de ações afirmativas na Ufopa}

A Ufopa foi criada pela Lei no 12.085 , de 5 de novembro de 2009, a partir da integração do Campus de Santarém da Universidade Federal do Pará (UFPA) e da Unidade Descentralizada Tapajós da Universidade Federal Rural da Amazônia (UFRA), ambas com atividades na região oeste do Pará. Nessa integração, foram incorporados e criados campi nas demais cidades da região: Óbidos, Oriximiná, Itaituba, Juruti, Monte Alegre e Alenquer.

No ano seguinte, em 2010 instituiu-se ainda, sob a tutela e a coordenação da UFPA, o primeiro Processo Seletivo Especial Indígena (PSEI). Com critérios avaliativos específicos, o Processo Seletivo Especial (PSE) é composto de prova de redação em língua portuguesa e entrevista, sem exigência de realização do Exame Nacional do Ensino Médio (Enem). É organizado por comissão própria, cuja atribuição é organizar e executar as etapas do processo, além de acompanhar e desenvolver seminários de avaliação e escuta com as lideranças indígenas e os movimentos governamentais e não governamentais da região.

É importante notar que o PSEI da Ufopa inicia-se em 2010, sendo, portanto, anterior à implementação da Lei no 12.711, de 29 de agosto de 2012, 
que estabelece a obrigatoriedade de reserva de no mínimo 50\% das vagas nas universidades para estudantes que tenham cursado integralmente o Ensino Médio em escolas públicas, autodeclarados pretos, pardos e indígenas, e pessoas com deficiência (PCDs). Foi, a partir de então, efetivado o sistema de cotas no Processo Seletivo Regular (PSR), permanecendo a realização dos processos seletivos especiais. Até 2019, ocorreram 10 PSEIs e cinco processos seletivos especiais quilombolas (PSEQs), com a primeira edição em 2015.

A manutenção de processos especiais de acesso à universidade parece ser indício da aferida conexão da universidade com indígenas e quilombolas da região. As ações afirmativas, a partir do PSE, são interpretadas como um canal entre a instituição e a diversidade étnica do território. Todavia, é importante verificar a influência desses povos na implementação dessa conduta, para não incorrer no equívoco de considerar o PSEI e o PSEQ como políticas alheias às demandas dos povos indígenas e quilombolas.

Pereira (2017) destaca que a realização de seleção diferenciada para os povos indígenas foi reivindicação de lideranças indígenas, como os caciques dos povos do Baixo Tapajós, inicial e posteriormente, dos territórios do Alto e Médio Tapajós. Foi essa presença ativa que impulsionou a criação de uma política de ações afirmativas por meio do PSEI. O PSE foi, portanto, "uma conquista resultante de lutas, reivindicações e dos direitos dos povos indígenas aos espaços educacionais por meio de formas diferenciadas de acesso no ensino superior" (Pereira, 2017, p. 98).

Em atendimento ao Estatuto da Ufopa, em abril de 2014 foi criada a Pró-Reitoria de Gestão Estudantil dessa universidade. E, dentro de sua estrutura, foi implementada a Diretoria de Ações Afirmativas (DAA), uma demanda dos estudantes indígenas, que tinham, dentro da instituição, um coletivo organizado. O objetivo foi fortalecer as ações afirmativas na instituição, em especial aos indígenas, pela significativa presença deles na universidade. Mais tarde, a Diretoria absorveu outras demandas, envolvendo demais públicos, entre eles os estudantes quilombolas.

Atualmente, a DAA tem como atribuição o fortalecimento de ações afirmativas para estudantes indígenas e quilombolas; a implementação de programas e projetos que visem à permanência dos estudantes dos diversos cursos; a promoção de palestras, seminários, oficinas, exibição de filmes, debates; assim como outras atividades voltadas para a preparação de estudantes indígenas e quilombolas, visando ao nivelamento de aprendizagem.

No que diz respeito à primeira atribuição, é resultante da Política de Ações Afirmativas e Promoção da Igualdade Étnico-Racial, aprovada pela Re- 
solução no 200, de 8 de junho de 2017 - Consepe-Ufopa. No artigo 2º, destacase que essa política tem por finalidade a "defesa dos direitos humanos e a promoção do direito à diversidade cultural, a defesa dos direitos à igualdade étnicoracial, a busca da igualdade de gênero, a garantia dos direitos das pessoas com necessidades específicas". Além disso, tem por objetivos "a diminuição da desigualdade social e o combate a todo tipo de discriminação e preconceito" (Resolução n⿳⺈ 200/2017).

Assim, compreende como "ação afirmativa" um "conjunto de medidas e ações, específicas e especiais, necessárias para contribuir com a afirmação da dignidade, da identidade e da cultura de grupos discriminados e vitimados pela exclusão social", ocorridos no passado ou no presente, bem como com a diminuição da desigualdade social. Destina-se, prioritariamente, aos grupos historicamente excluídos: indígenas, negros, quilombolas, comunidades tradicionais, PCDs e população LGBT, com ênfase nas pessoas ingressantes por políticas que visem à equidade de direitos, como o Sistema de Cotas Sociais e o PSE (Resolução nº 200/2017).

$\mathrm{O}$ acesso às populações indígenas e quilombolas ao ensino superior tem sido uma política permanente nesses 10 anos da Ufopa. Contudo, há outros desafios de grande importância, que devem ser enfrentados pela instituição e que dizem respeito, especialmente, às condições financeiras e pedagógicas de permanência desses estudantes. Além disso, deve haver o combate ao preconceito e a inserção mais assistida desses grupos no espaço acadêmico.

\subsection{Indígenas nos cursos do Iced e no curso de História}

O PSEI é a principal política de ações afirmativas para ingresso de indígenas nos cursos de graduação da Ufopa. De acordo com os dados do Sistema Integrado de Gestão de Atividades Acadêmicas (Sigaa), desde a primeira edição, em 2010, o processo já promoveu a entrada de 534 indígenas de diversas regiões do estado e de diversas etnias (Sigaa, 7 maio 2019).

Atualmente, a universidade tem 449 estudantes indígenas ativos, estando 138 matriculados no Iced, ou seja, 31\% dos estudantes indígenas da Ufopa estão no Iced (Sigaa, 15 abr. 2019). Se considerarmos que ao todo a universidade tem sete institutos, conclui-se que o destino da maior parte dos estudantes indígenas são os cursos do Iced.

Todavia, verificou-se que, até 15 de abril de 2019, o número de cancelamentos de vínculo dos estudantes indígenas da Ufopa em geral, sem considerar a motivação, foi maior que o número de concluintes. Foram 45 cancelamen- 
tos e 30 conclusões. No Iced, a questão inverte-se, pois foram 18 conclusões, em detrimento de 11 cancelamentos.

O número de cancelamentos chama atenção. Embora não se tenha análise qualitativa que aponte as razões para esses dados, é evidente a necessidade de estabelecer ações de apoio e acompanhamento dos estudantes indígenas. Ora, o acesso diferenciado pressupõe também estratégias de apoio pedagógico durante o percurso acadêmico.

Na Política de Ações Afirmativas e Promoção da Igualdade ÉtnicoRacial da Ufopa, o acompanhamento está previsto no artigo 11, em que se lê sobre a criação de comissões setoriais, compostas por docentes, técnicos e discentes, cuja função é "acompanhar a elaboração, implementação e avaliação da política, seus instrumentos e ações” (Resolução no 200/2017). Da análise do artigo 13, que versa sobre as competências dessas comissões setoriais, é possível sintetizar as ações em duas frentes principais: promoção da igualdade étnicoracial e combate ao racismo e ao preconceito; e acompanhamento pedagógico do percurso acadêmico por meio de estratégias que garantam a permanência no itinerário acadêmico.

Essas perspectivas de ação vinculam-se à constatação das dificuldades encontradas pelos estudantes no ambiente universitário. Ora, é importante lembrar que a universidade ainda é um espaço que reflete a cultura hegemônica e eurocêntrica. A presença da diversidade étnica, racial, social no ensino superior significa o enfrentamento da postura elitista que historicamente caracterizou o ambiente das universidades. Esse é um pressuposto para que se efetive o atendimento das minorias excluídas desses espaços de formação.

Terezinha do Socorro Lira Pereira (2017) constatou, por meio de pesquisas com os estudantes indígenas, que problemas encontrados no ambiente universitário são, sobretudo, relativos ao idioma e à precária formação da educação básica. No que se refere ao idioma, principalmente, os estudantes indígenas não falantes da língua portuguesa apresentam dificuldades em comunicação, leitura e interpretação dos materiais disponibilizados nas disciplinas e no desenvolvimento das atividades acadêmicas. Além disso, a formação precária da educação básica impacta negativamente o percurso acadêmico dos alunos indígenas.

Eveline Sousa e Diego Góis (2017), ao analisarem os estudantes indígenas waiwai, arapium e tupinambá, também verificaram essas mesmas problemáticas. Assim como Pereira (2017), identificaram outros problemas, como o distanciamento da família e da aldeia, a adaptação ao modo de vida urbano na cidade e condições financeiras difíceis, além do preconceito dos docentes e co- 
legas não indígenas, vivenciado pelo isolamento e pela rejeição nas atividades em sala de aula e em demais ações na universidade.

A partir dessas problemáticas, parece haver, nesses 10 anos da Ufopa, uma incongruência. Verifica-se a manutenção de PSE para ingresso de alunos indígenas e o auxílio estudantil (moradia, material didático, transporte e alimentação). Todavia, no que se refere ao acompanhamento pedagógico, a instituição ainda não conseguiu estabelecer uma política efetiva e contínua que tenha impacto positivo na permanência e no rendimento acadêmico desses alunos.

Nesse aspecto, convém mencionar a Formação Básica Indígena (FBI) como uma política afirmativa positiva da instituição, implantada oficialmente em 2017. Instituída pela Resolução no 194/2017 - Consepe/Ufopa, foi concebida como um processo de formação básica inicial, em ensino superior, destinada aos alunos indígenas provenientes do PSEI, com duração de dois semestres, contemplando conteúdos das seguintes áreas: ciências exatas, ciências humanas, tecnologias e letras - língua portuguesa, desenvolvidos por meio de ações de ensino e extensão. Tem como principal objetivo mensurar a proficiência em ciências exatas, humanas, tecnologias e letras dos estudantes indígenas recémingressados na Ufopa, visando a proporcionar sua excelência acadêmica com expectativa na diminuição da retenção e evasão universitária.

Por outro lado, ao final do primeiro ano de ingresso na Ufopa, os alunos desligam-se das ações da FBI e passam a integrar o percurso acadêmico de seu curso, e é nesse espaço que persiste a maioria das dificuldades elencadas pelos estudantes, pois ainda há um distanciamento entre o projeto desenvolvido na FBI e os projetos pedagógicos dos cursos. Ao que parece, é necessário garantir o acompanhamento e o apoio contínuo, ao adentrarem seus cursos específicos, a fim de possibilitar a continuidade das ações desenvolvidas na FBI e, assim, promover condições de apoio para a permanência com melhores rendimentos dos estudantes indígenas.

Se verificarmos, em particular, os estudantes indígenas vinculados ao curso de Licenciatura em História, desde a primeira edição do PSEI, em 2010, constata-se o ingresso de 27 estudantes indígenas no curso. Estando em análise os matriculados, concluídos e cancelados, bem como o tempo regulamentar de curso, obtêm-se os seguintes dados: 
Quadro 1 - Situação de vínculo de estudantes do curso de História

\begin{tabular}{|l|c|}
\hline Situação de vínculo & Quantitativo \\
\hline Ativo & 20 \\
\hline Concluído & 5 \\
\hline Cancelado & 2 \\
\hline Total & $\mathbf{2 7}$ \\
\hline
\end{tabular}

Fonte: Sigaa, 7 maio 2019.

Quadro 2 - Tempo de curso dos estudantes ativos do curso de História

\begin{tabular}{|l|c|}
\hline Tempo de curso & Quantitativo \\
\hline Dentro do tempo regulamentar de curso & 9 \\
\hline Fora do tempo regulamentar de curso & 11 \\
\hline Total & $\mathbf{2 0}$ \\
\hline
\end{tabular}

Fonte: Sigaa, 7 maio 2019.

Dos dados apresentados, verificam-se duas questões relacionadas entre si: a primeira refere-se à saída de alunos indígenas — dos 27 ingressantes, apenas cinco concluíram o percurso acadêmico. É o que reflete o Quadro 2: dos 20 alunos com matrícula ativa, 11 estudantes estão fora do tempo regulamentar do curso. Acrescenta-se ainda que todos os cinco alunos que já concluíram ultrapassaram o tempo regulamentar do curso, ou seja, levaram mais tempo para conclú́-lo do que o previsto no percurso acadêmico.

O tempo regulamentar do curso de História é de nove semestres para ingressantes até 2015 e de oito semestres para ingressantes a partir de 2016. Os dados mostram que 55\% dos estudantes ativos estão fora do tempo regulamentar do curso. Esse indicativo deve ser analisado com mais profundidade, para entender os fatores que levam mais da metade dos estudantes a permanecer além do tempo médio do curso e quais ações podem ser implementadas para a superação das dificuldades existentes.

Por outro lado, pode-se afirmar que a retenção espelhada no Sigaa pode estar relacionada com as problemáticas verificadas pelos estudantes indígenas no ambiente universitário, conforme apontaram as pesquisas de Terezinha Pereira (2017) e Eveline Sousa e Diego Góis (2017). É também o que têm apontado os resultados coletados em ações desenvolvidas pela Comissão Setorial de Ações Afirmativas do Iced.

Em novembro de 2018, por exemplo, foi realizado o I Encontro de Ações Afirmativas do Iced, cujo objetivo foi, por meio de grupos de trabalho (GTs), ouvir os estudantes negros, quilombolas, indígenas, PCDs e população LGBT, que são públicos atendidos pela política de ações afirmativas. Os estu- 
dantes indígenas do Iced expuseram suas experiências, dificuldades e vivências na universidade, bem como apresentaram suas pautas e sugestões para melhor atendimento dos estudantes indígenas na instituição.

Entre os problemas apontados pelos estudantes indígenas, destaca-se o preconceito vivenciado na sala de aula vindo dos estudantes, e em alguns casos dos próprios professores. De acordo com os indígenas, alguns professores não se preocupam com a aprendizagem, partindo do princípio de que eles não aprendem, não conseguem entender os conteúdos. No que diz respeito à metodologia, como atividades em grupo, os alunos indígenas são pouco inseridos, e nas avaliações, por exemplo, não são consideradas as especificidades da língua (Relatório do GT Indígena, Comissão Setorial de Ações Afirmativas do Iced, 2018).

Os estudantes indígenas apontaram ainda que, para a superação dessas dificuldades, são necessárias ações mais sistemáticas, que promovam a efetivação da Resolução n⿳o 200/2017. Além disso, destacaram como importantes o reconhecimento da diversidade de língua e cultura, a implementação de monitorias para acompanhamento dos alunos indígenas, o atendimento diferenciado para esses estudantes, especialmente para os que têm filhos. Ressaltaram também o fortalecimento da demanda de criação de um instituto intercultural, considerando o número de indígenas, com seus costumes e culturas diferentes (Relatório do GT Indígena, Comissão Setorial de Ações Afirmativas do Iced, 2018).

Os estudantes indígenas ressaltaram que, para a melhoria do percurso acadêmico e a permanência na universidade, são necessários: o combate ao preconceito e ao racismo, tendo sido sugerida a discussão ampla sobre a cartilha de combate ao racismo; o acompanhamento teórico (leitura e discussão de textos); a contratação de intérpretes para os discentes bilíngues; a implementação de mecanismos de informação sobre as especificidades dos alunos indígenas; a garantia de um monitor indígena para cada curso; a realização de formação ao docente na semana de planejamento do Iced; e a criação de editais de mobilidade interna para indígenas (Relatório do GT Indígena, Comissão Setorial de Ações Afirmativas do Iced, 2018).

Conforme se verifica, o ingresso dos alunos indígenas é apenas a primeira etapa para a promoção da diversidade na universidade. Os entraves para sua permanência, vinculados às dificuldades enfrentadas por eles nos cursos, parecem grandes barreiras a ser transpostas. Se, nesses 10 anos da Ufopa, a instituição promoveu o acesso de indígenas por meio do PSEI, apresenta-se como desafio atual a implementação de políticas que efetivem o aprendizado, o cum- 
primento do percurso acadêmico, a inclusão e o combate ao preconceito dentro da universidade.

A análise das demandas dos estudantes indígenas, como verificamos, aponta que é necessário que a conexão também se efetive internamente. Ao que parece, a instituição ainda tem um longo caminho a ser percorrido no que diz respeito à assistência pedagógica, ao acompanhamento do percurso acadêmico, às metodologias, bem como à superação de estigmas e preconceitos. São ques tões que implicam diretamente a formação e a prática docente.

A presença da diversidade étnica, cultural e social na Ufopa implica a necessidade de repensar a prática docente. Conforme se verifica, um elemento central, levantado pelos estudantes indígenas, refere-se às metodologias. É importante desenvolver formação para encontrar alternativas metodológicas que contemplem a diversidade e a inclusão. Essa formação docente deve balizar-se na perspectiva da educação intercultural, do conhecimento da diversidade dos povos indígenas de nossa região e de posturas afirmativas nas práxis educacionais de combate às posturas de preconceito e estereótipos.

Nessa perspectiva, que visem ao reconhecimento da cultura tradicional indígena e, sobretudo, à aceitação do acadêmico indígena como cidadão capaz de estar na universidade. Tais orientações exigem uma postura que caminhe na contramão do sistema educacional atual, com raízes profundas historicamente construídas, com fortes elementos de exclusão e discriminação. É necessário, portanto, que as políticas de ações afirmativas e os estudantes alvo dessas políticas de fato integrem o ambiente universitário e sejam aceitos e inseridos, de forma que possam fortalecer-se como sujeitos sociais e políticos.

\section{Considerações finais}

"As minorias têm que se curvar às maiorias." Assim, em meio aos gritos de apoiadores, o então presidente do Brasil, Jair Bolsonaro, proferia um de seus discursos no período eleitoral. E completava o absurdo: "ou as minorias se adaptam, ou simplesmente desaparecem". Uma postura vergonhosa, que escancara e diz muito sobre a sociedade brasileira.

Não por acaso, as minorias que o presidente quer que se curvem são os grupos alvo das políticas de ações afirmativas: negros, indígenas, mulheres, população LGBT, quilombolas e PCDs. As atitudes que vêm sendo tomadas pelo governo Bolsonaro sem dúvida ameaçam a permanência das políticas afirmativas. É evidente, por exemplo, que o corte de 30\% dos recursos das universida- 
des terá impacto negativo sobre a efetivação de acesso, permanência e percurso de estudantes atendidos pelas ações afirmativas. É, sem dúvida, um grande retrocesso, quando compreendido pelos quadros da percepção histórica.

Todavia, para opróbrio do presidente Bolsonaro, as minorias não vão desaparecer, e, ao que parece, nem curvar-se. Nos últimos anos, negros, indígenas, quilombolas, mulheres, população LGBT e PCDs reafirmaram-se contra os preconceitos, a discriminação e a exclusão, que marcam suas existências cotidianas, e organizaram-se politicamente. Dessa forma, assim como os povos indígenas contrariaram as perspectivas do desaparecimento étnico no século XIX, esse mesmo fenômeno mantém as minorias em movimento.

E, já que estamos tratando de "reflexões e existências", nada mais oportuno que terminar por aqui, reafirmando a importância das universidades públicas para a existência política e ativa das minorias. Ora, se, nesses 10 anos, a Ufopa manteve políticas voltadas ao ingresso de estudantes alvo da política de ações afirmativas, em especial os indígenas, parece-nos ser necessário e urgente, sobretudo nesse contexto, fortalecer ainda mais os fios com os quais a universidade se conecta com a diversidade étnica e cultural da Amazônia.

\section{Referências}

ALMEIDA, Maria Regina Celestino de. Metamorfoses indigenas: identidade e cultura nas aldeias coloniais do Rio de Janeiro. Rio de Janeiro: Arquivo Nacional, 2003.

Os índios na história do Brasil no século XIX: da invisibilidade ao protagonismo. Revista História Hoje, v. 1, n. 2, p. 21-39, 2012.

BANIWA, Gersem. Educação escolar indígena no Brasil: avanços, limites e novas perspectivas. In: 36를 REUNIÃO DA APEND. Anais [...], Goiânia, 29 set./2 out. 2013.

O indio brasileiro: o que você precisa saber sobre os povos indígenas no Brasil hoje. Brasília: Ministério da Educação: Secretaria de Educação Continuada, Alfabetização e Diversidade: Laced/Museu Nacional, 2006.

COELHO, Mauro Cezar. Do sertão para o mar: um estudo sobre a experiência portuguesa na América, a partir da colônia: o caso do diretório dos índios (1751-1798). 2005. Tese (Doutorado) - Programa de Pós-Graduação em História Social, Universidade de São Paulo, São Paulo, 2005. 
CUNHA, Manuela Carneiro da. Imagens de índios do Brasil: o século XVI. Estudos Avançados, v. 4, n. 10, 1990.

HENRIQUE, Márcio Couto. Sem Vieira, nem Pombal: índios na Amazônia do século XIX. Rio de Janeiro: Eduerj, 2018.

JENSEN, Geziela. Politica de cotas raciais em universidades brasileiras: entre a legitimidade e a eficácia. Curitiba: Juruá Editora, 2010.

KAUFMANN, Roberta Fragoso Menezes. Ações afirmativas à brasileira: necessidade ou mito. São Paulo: Revista dos Tribunais, 2007.

MAHER, Terezinha Machado. Formação de professores indígenas: uma discussão introdutória. In: GRUPIONI, Luís Donizete Benzi (org.). Formação de professores indígenas: repensando trajetórias. Brasília: Ministério da Educação: Secad, 2006. p. 11-37.

MONTEIRO, John. Negros da terra: índios e bandeirantes na origem de São Paulo. São Paulo: Companhia das Letras, 2005.

PEIXOTO, Rodrigo Correa; ARENZ, Karl; FIGUEIREDO, Kércia. O movimento indígena no Baixo Tapajós: etnogênese, território, Estado e conflito. Novos Cadernos NAEA, v. 15, n. 2, p. 279-313, dez. 2012.

PEREIRA, Terezinha do Socorro Lira. Os indígenas e o ensino superior na Amazốnia: realidade e perspectivas da política de ação afirmativa da Universidade Federal do Oeste do Pará (2010-1015). 2017. Dissertação (Mestrado) - Instituto de Ciência da Educação, Programa de Pós-Graduação em Educação, Universidade Federal do Oeste do Pará, Santarém, 2017.

RAMINELLI, Ronald. Imagens da colonização: a representação do índio de Caminha a Vieira. São Paulo: Edusp: Fapesp; Rio de Janeiro: Jorge Zahar, 1996.

SOUSA, Eveline Almeida de; GÓIS, Diego Marinho. Estudiantes indígenas en la Universidad Federal del Oeste De Pará (Ufopa), Santarém (Brasil): waiwai, arapium y tupinambá. Boletín Americanista, Barcelona, ano LXVII, v. 2, n 75, p. 113-131, 2017.

\section{Fontes}

INSTITUTO BRASILEIRO DE GEOGRAFIA E ESTATÍSTICA (IBGE). Censo 2010. 
UNIVERSIDADE FEDERAL DO OESTE DO PARÁ (UFOPA). Conselho Superior Universitário. Resolução nº 200. Pará, 2017.

UNIVERSIDADE FEDERAL DO OESTE DO PARÁ (UFOPA). Editais de Processo Seletivo Especial Indígena (PSEI).

UNIVERSIDADE FEDERAL DO OESTE DO PARÁ (UFOPA). Plano de Desenvolvimento Institucional (PDI).

UNIVERSIDADE FEDERAL DO OESTE DO PARÁ (UFOPA). Relatórios da Comissão Setorial de Ações Afirmativas do Instituto de Educação, 2018.

UNIVERSIDADE FEDERAL DO OESTE DO PARÁ (UFOPA). Sistema Integrado de Gestão de Atividades Acadêmicas (Sigaa). 